\title{
No se ve nada
}

\author{
Françoise Dubor ${ }^{\bullet}$ \\ Université de Poitiers \\ Traducción del francés: \\ Silvia Zenarruza de Clément ${ }^{\bullet \bullet}$ \\ Universidad Nacional del Litoral
}

\section{Resumen}

El texto del escritor francés Pierre Michon, titulado Les Onze (Los once) permite considerar cómo se cruzan los regímenes de representación en ese texto, que son tan variados como ricos: literario, teatral, pictórico, museístico, histórico. Se trata de un cuadro que representa el Comité de Salvación Pública, bajo el Terror, durante la Revolución francesa. Pero el principio de este texto es su confrontación a lo irrepresentable, de allí una multiplicidad de estrategias para perfilar esta representación aporética. La manera en que los diversos regímenes de representación se responden, se completan, compiten entre sí, o se repiten, conduce a una reflexión sobre la manera en que el sentido se construye y evoluciona según el régimen de representación elegido, es decir, según su soporte. En definitiva, parecería que la representación fuese una imagen separada de todo objeto, de la que se trata de comprender el sentido y la función.

\section{Palabras clave}

- Representación · Visión · Soliloquio · Pintura · Literatura · Texto Imagen

\footnotetext{
- Maître de conférences HDR en Literatura francesa y Estudios teatrales en la Universidad de Poitiers (Francia). Autora de obras sobre el monólogo, sobre varios autores dramáticos contemporáneos, de Beckett a Lagarce, trabaja sobre las cuestiones de la representación y de la imagen, desde las vanguardias artísticas del comienzo del siglo XX. Especialista en dramaturgia y estética de la escena contemporánea. - Licenciada en Literatura y Lenguas Modernas, Profesora en Letras, Profesora de Francés. Profesora adjunta ordinaria de Literatura Francesa e Italiana en la Facultad de Humanidades y Ciencias y Adjunta de Francés en la Facultad de Ingeniería Química de la Universidad Nacional del Litoral. Profesora en el ISP NN 8 «Almirante Brown». Directora de la Alianza Francesa de Santa Fe. Autora de numerosos artículos. Codirectora CAID-UNL dirigido por Adriana Crolla.
} 


\section{Abstract}

The text from the French author Pierre Michon, named Les Onze, allows the study of the interaction between different ways of representation within this text, which are as diverse and rich: the literary, the theatrical, the picturesque, the museistic, the historical. This painting represents the Committee for Salut Public, under the period of the Terror, during the French revolution. But the principle of this text is its confrontation to the irrepresentable. Hence the multiplicity of interpretive strategies that can be applied to this aporetic representation. The way in which these different levels of representation interrelate, complement each other, compete with each other and even repeat themselves, all are conducive to a reflection about the way in which meaning is constructed and evolves by way of the representational system selected or, in other words, the representational support. Thus, the representational levels seem to be conveyed by an image separated from its object, one whose meaning and function have yet to be understood.

\section{Keywords}

- Representation · Vision - Soliloquy · Painting - Literature - Text . Image

Los Once de Pierre Michon es un texto corto de 126 páginas que describe la existencia de un cuadro que representa el Comité de la Salvación Pública, con los once miembros que fueron reunidos en los momentos más negros de la Revolución Francesa: el Terror (5 de septiembre de 1793 - 28 de julio de 1794). El único problema es que el cuadro y su pintor no existen, contrariamente al episodio histórico representado. Las estrategias para hacer visible un cuadro invisible y conocer un pintor inexistente se multiplican en el texto de Michon, por lo que los esfuerzos no carecen de un regodeo gozoso y que nos propone en definitiva una interesante cuestión: ¿de qué cosa es soporte la representación?

Es por esto que al momento de comenzar, como es de esperar, por el texto de Pierre Michon $^{1}$, pienso más bien en Daniel Arasse, de quien tomo en préstamo el título de su ensayo publicado en 2000. Este último no tiene nada que ver con el primero. Pero, por caminos opuestos, los dos nos invitan a mirar un cuadro con una mirada nueva.

El narrador del relato de Daniel Arasse evoca seis cuadros célebres y nos incita a mirar cada cuadro con una mirada nueva, es decir, abandonando las ideas recibidas, poniendo atención al detalle, sin buscar fuera del cuadro elementos de su interpretación (por la biografía del artista, el academicismo de la época, las tendencias contemporáneas y otras informaciones circunstanciales). Nos incita a interrogar las anomalías que identificamos sobre la tela misma. Nos incita a abandonar nuestros saberes para recibir el cuadro "como si no supiésemos nada». Así, nos propone 
mirar Marte y Venus sorprendidos por Vulcano del Tintoretto, La Anunciación de Francesco del Cossa, La Adoración de los magos, de Bruegel, La Venus de Urbino, de Tiziano, Olympia, de Manet, Las Meninas, de Velázquez y sin olvidar la cabellera de María Magdalena, tema que es objeto de diversos tratamientos según los cuadros y sus pintores.

Para decir las cosas con claridad, aunque todo el mundo lo sabe hoy, el cuadro que da título al texto de Pierre Michon no existe, ni su pintor, ni las referencias que él provee y que podrían servir para certificar para su existencia. En ese caso, todo es humo. Humo... no exactamente: es de la representación de lo que se trata.

Me gustaría mostrar aquí que esta es la cuestión principal de Michon. Por supuesto, en este campo, las dos artes favorecidas son la pintura y la literatura: el texto tiene la misión y la función de representar ese cuadro. Todo reposa entonces, sobre la imagen visual y ella misma, sobre la palabra. Pierre Michon tiene razón al tratar de seducirnos con ese cuadro, puesto que se inscribe en una tradición antigua. Pintores como Frans Hals han pintado muchos retratos de grupos, de personalidades eminentes, autoridades y otras cofradías profesionales diversas, desde el siglo anterior a la época que él trata; la del Terror, en la Revolución Francesa. Tenemos entonces a priori algunas ocurrencias en la cabeza, una cierta idea de lo que representa el cuadro.

Pero subrayemos bien este detalle: los grupos en cuestión, en la tradición pictórica, cuentan cinco, seis, ocho, doce o dieciocho miembros. Y si nos limitamos a la obra pintada por François-Elie Corentin, se trata también de su obra de 1784, la serie de Las Sibilas que son habitualmente diez o doce. Sin embargo, se nos aclara en el texto de Michon muy tarde, que son cinco (II, 3, 118) y no once. El título es entonces acertado pues es suficiente para especificar el cuadro en cuestión. El detalle cuenta. El autor apuesta sobre nuestro deseo de ver el cuadro prometido, por el simple horizonte de expectativa que crea el título del texto.

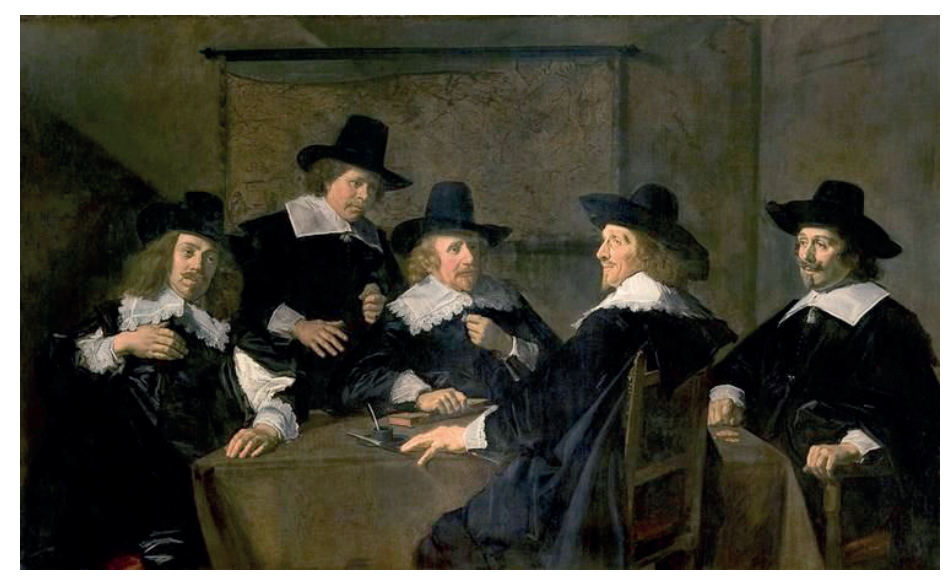

Los Regentes del Hospital Sainte-Elizabeth de Haarlem. Franz Hals, 1641 


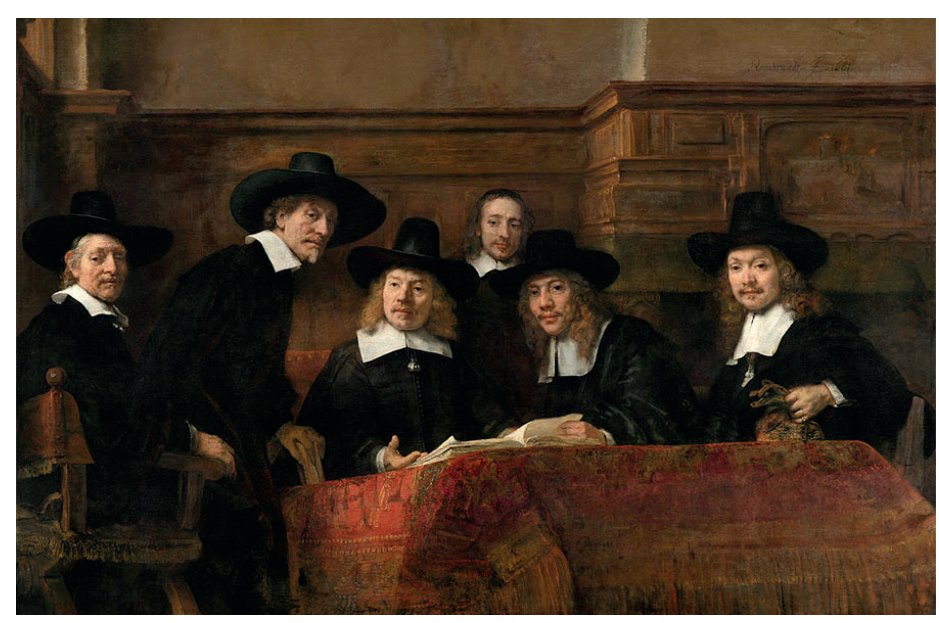

Síndico del gremio de los pañeros. Rembrandt, 1662.

En efecto, con Pierre Michon, entrar en el texto significa una entrada en la pintura puesto que el título es el del cuadro que en consecuencia esperamos ver, describir, leyendo un texto. Pero la imagen será sugerida, suscitada, evocada solo por las palabras. Será necesario que estas logren hacer surgir la imagen del cuadro para que podamos analizarlo, admirarlo o simplemente conocerlo. Lo menos importante es ver ese cuadro. Si apenas sabemos de lo que el autor quiere hablarnos no faltan las sugerencias visuales: nos remitimos a numerosas referencias. Y por supuesto, cuenta también con eso.

Contrariamente a Daniel Arrase que evoca pinturas conocidas por todos, Michon inventa para nosotros ese famoso cuadro - que recuerda a tantos otros, bien conocidos, vistos antes. En el mejor de los casos, vamos a percibirlo. El autor vuelve a él varias veces en el presente de enunciación de la primera parte, con una presentación lacónica del cuadro, en una visión fugitiva, es decir en unas líneas: es un cuadro que se venga de toda una parte de la historia del arte italiano recibida bajo la expresión de «la buena vida», expresión misma que se encuentra más tarde en el texto de Pierre Michon. El cuadro Les Onze provoca una ruptura pues es percibido como un acto de destrucción en terrible gozo (de «carne, paño, seda, fieltro»). Es un cuadro que tiene que ver con lo sagrado y el sacrificio (se trata de once estaciones, sin duda en relación con el número de personajes representados, tanto en el título del cuadro como en el del texto: alude así al calvario hasta la crucifixión, sin el descenso al sepulcro). Este cuadro es presentado como un texto, puesto que se dice de él que habla «un lenguaje de tinieblas» (I, 1, 16). Las últimas líneas del primer capítulo agregan que la existencia del cuadro se debe a la de los once personajes que él representa, y que es entonces esta historia lo que se trata de contar: una historia conocida y una doble historia puesto que se trata de la de los Once, y de la del cuadro que los representa: historia de los personajes salidos del lienzo.

Al terminar el primer capítulo en esta primera parte, el lector tiene idea de que este cuadro no es objeto de la pintura, sino que es literalmente una narración: un cuadro no pictórico sino literario. Y que esta literatura trata de una porción de la Historia. Henos aquí ya entre lo real y la ficción. Un real pasado sostenido por un 
relato presente, es ya un filtro que da a la Historia su dimensión de transmisión fuera del tiempo. Entra en nuestra herencia cultural e histórica común y elevada al rango de legado, como muchos otros datos históricos y culturales que entran para siempre en nuestro imaginario colectivo.

De allí la relación con el capítulo siguiente (I, 2, 25: «El autor de los Once»). El término es genérico pero tanto más interesante cuanto que este «autor» es el pintor del cuadro, según el relato que va a desarrollarse. La superposición (autor del relato/autor del cuadro) permite a Michon asumir su parte de responsabilidad, por medio de su narrador, en la existencia de ese cuadro calificado pero aún invisible.

Esta cuestión del autor del cuadro tiene también su virtud estructurante, ya que no se contenta con inaugurar el capítulo, lo cierra igualmente, esta vez con una nueva claridad en los términos: «François-Elie Corentin, el Tiépolo del Terror, quien pintó los Once» (I, 2, 42). La genealogía misma fija a ese joven pintor una paternidad interesante: está presentado como el hijo de la poesía y del ideal, dos ficciones inversamente tratadas, la sangre roja adicionada de sangre azul, la mezcla de la legitimidad y de la ilegitimidad (con un padre plebeyo y una madre de pequeńa nobleza). Volveremos in fine sobre la particular genealogía que fija el destino del pintor, fuera de los caminos trillados, y que le proporciona modelos de representación contradictorios. En fin, se puede comenzar diciendo que la literatura da nacimiento a la pintura, a su imagen: la de una «impecable reversión».

A la vez introductorio y conclusivo, el cuadro de los Once cierra el capítulo 2 y abre el capítulo 3: es una apertura estruendosa, con una apelación, una orden gracias a la enumeración. El cuadro que no existe está aquí presentado con un aplomo innegable, por todos los nombres de los personajes representados, su función colectiva, el grupo que forman y por el formato del marco también. El cuadro se vuelve una especie de ventana abierta de golpe, está listo para entregar su espacio de visión. Pero lo que sigue explica sobre todo su carácter improbable (no habría que haber exhibido esos hombres como ídolos, como tiranos cuyas imágenes serían idolatradas, porque constituye un riesgo interesante para nosotros que prestamos mucha atención a los regímenes de representación convocados). Michon termina precisando el formato del lienzo en aproximadamente: «cuatro metros por tres» (I, 2, 30): «cuatro metros coma treinta por tres, un poco menos de tres» (I, 3, 43). Esto permite al menos entender al cuadro por lo que es: un cuadro $-\mathrm{y}$ no, como antes, un texto o un golpe de efecto- - algo que surge de manera inopinada. Sin embargo, estas precisiones sorprendentes van a tener la misma suerte que las menciones precedentes, pues, apenas esbozadas, son inmediatamente borradas; la visibilidad del cuadro es volátil, cae en la indistinción: «¿Los ven? Uno tiene dificultad en captarlos a todos a la vez... con tantos reflejos en el vidrio» (I, 3, 44). Nos ha permitido aprehender el tema, pero ¿̨verlo? El narrador nos muestra que no se ve nada. Es un juego, también: este narrador aparece como un charlatán, o un jugador de cartas, si persistimos en querer ver el cuadro prometido desde el título. En lugar de ver nos es posible leer: «usted es lector (...) usted es (del Siglo) de las Luces también a su manera» (I, 3, 51-52). Es decir que somos poseedores de un saber (el que Daniel Arasse recomendaba abandonar en el umbral del cuadro - y Michon también - si se tiene en cuenta la vanidad de la «antecámara explicativa», justo antes de entrar en la sala del pabellón de Flore, en el Louvre, donde estaría el cuadro). Pierre Michon, mientras tanto, nos hace asistir a la revancha de la literatura sobre la pintura que muestra la obra maestra invisible. Pero, jes realmente el 
cuadro lo que nos muestra, o bien es esa escena, que tuvo lugar al comienzo de la Revolución Francesa? Lo que perturba es el lugar, un museo acogiendo los cuadros de la Historia, el Louvre es también un lugar de citas bajo la Revolución, y en particular, el segundo piso del pabellón de Flore, el lugar preciso donde se reunía el Comité de Salvación Pública. Si no vemos lo que solo el texto puede mostrarnos, ¿es porque se trata de una escena histórica que hoy solo podemos imaginar como una realidad pasada? ¿Es porque el cuadro representando esos miembros reunidos, es un engaño significativo, una representación inexistente que opera sin embargo con toda su fuerza sobre el terreno simbólico, estético, histórico?

El texto solo nos muestra el cuadro, en sentido propio o en sentido metafórico. Se lo comprende sobre todo puesto que la galería de los retratos es reconsiderada, rehecha, según las aspiraciones de esos Señores que no vemos, pero, ellos sí, nos miran, con su esperanza de gloria, como nos cuenta el texto. Esta gloria no viene de las letras, ninguno es «un hombre de letras». Todos son escritores fallidos. El único escritor al que podríamos referir aquí es el nuestro: Michon en persona. Pero él tiene cuidado de desaparecer detrás de su narrador que no es escritor - no es un «hombre de letras», ni un hombre de palabra, puesto que no cumple lo que promete. Sería más bien un hombre de la palabra. Se contenta con relatar: es un presentador oral. Cuenta entonces la vida de hombre de cada personaje en el cuadro, con sus aspiraciones y sus esperanzas frustradas. Compite con la antecámara explicativa del Louvre, cae en la noticia biográfica, con la única pero consecuente ventaja de erigir, sin efecto demostrativo, la gloria literaria en un monumento indiscutido para la posteridad. Es tal vez un ideal que pertenece a las Luces, persistiendo en el momento de redactar el cuadro de los Once. El narrador lo sabe bien: «todo eso está marcado en los recordatorios: eso no se ve sobre el cuadro» (I, 3, 57). La glosa de coloración erudita, sobre los pequeños paneles explicativos típicos de los museos (o «recordatorios») recae sobre aquello por lo que era desde un principio denunciado: la vanidad.

El capítulo termina con una nueva hipótesis de lectura, que hace de los once hombres once veces la figura del padre, once veces la revancha irreal de su padre poeta, y entonces, once veces su derrota, de pie. Para el narrador, la figura de su padre es en definitiva el objeto, no ya de una interpretación, sino de un reconocimiento cierto, en el momento en que pone el acento sobre otra cosa: el rostro finalmente (re)conocido es sin embargo desnaturalizado por la función que asume. Pues se trata de once asesinos de rey: dicho de otra forma, once parricidas. Así el personaje se encuentra atrapado entre parricidio y suicido, entre una existencia ideal y la nada de la muerte. Se trata de aquél cuya existencia misma es ilegítima: la encarnación imposible por excelencia puesto que a la vez existe pero no tiene ninguna existencia, vale decir, "un escritor Lemosino $»^{2}$ (no solamente una expresión de Michon, sino también un pálido pero veraz reflejo del Michon, él mismo Lemosino). Como la Sombra Doble en Claudel, que existe pero no tiene ningún derecho a la existencia, representando esta unión prohibida entre dos seres como otra encarnación imposible.

Aquíse trata de la exacta figuración de la brutal violencia que es el Terror. Pero con Pierre Michon, aún la pesadumbre es liviana. Termina su capítulo poniendo en duda el principio mismo de la interpretación: es una cuestión de reflejo, de luz y sobre todo de punto de vista: «Vean cómo los reflejos cambian sobre el vidrio cuando uno se desplaza un poco. (...) Dos pasos más y todo es oscuro» (2009:58). El cuadro es una boca de lobo: antes aún de que se pueda asirlo, todo se deshace ante nuestros ojos. 
En el capítulo siguiente el narrador adopta la mirada del niño y aprende así lo que veía ese futuro pintor, mira por sus ojos lo que ha constituido su visión familiar y sorprendente de sus ańos jóvenes. Al hacer esto, construye ese nuevo cuadro de una trinidad familiar, el joven y futuro pintor rodeado de dos mujeres - madre y abuela. Pero para hacer esto, falta el cuarto término, el del narrador: la insinuación de la mirada, como un parásito que insinúa el deseo en el marco familiar idílico. La expresión y el alcance de esa mirada están sostenidos por los juegos de mirada justamente - la del niño sobre el Lemosino, la del Lemosino sobre la falda de la madre del pintor. Este Lemosino es «usted o yo» (I, 4,70), por lo que se puede por turnos contribuir al cuadro y mirarlo constituirse. El cuadro - todo cuadro - nunca termina de elaborarse, no se ve de él más que un esbozo, una forma a perfeccionar, una obra inacabada. No solamente el alcance, sino la identificación misma de la mirada reviste una importancia particular, en el cierre del capítulo 4 de la primera parte: la mirada prohibida del niño sobre el deseo entre el Lemosino y su madre, como la mirada que lleva el nińo sobre el Lemosino o la que la madre (o la abuela) lleva sobre el niño, es «la demasía de deseo y lo tan poco de justicia» (I, 4.74): es el marqués de Sade y Jean-Jaques Rousseau. Es el mundo campesino, natural de la infancia, visitado por el despertar del deseo imperioso, tiránico, sordo y ciego de pronto a toda otra razón. La definición del Terror se decide y se dibuja a partir del tiempo de la infancia. Pero la literatura, una vez más, tiene la última palabra. Es con ella que se puede volver al cuadro. Esta primera parte le da preferencia a lo que refuta Daniel Arasse para una buena visibilidad-legibilidad del cuadro: la biografía del artista. Lo que pasa sin embargo da la razón a Daniel Arasse, pues si las condiciones de emergencia de un mundo tal como el del Terror se le han aparecido así al corazón improbable del Lemosino (pero ¿̇por qué no aquí más que en otra parte?), sigue sin verse el cuadro anunciado.

La segunda parte cuenta el encargo del cuadro, es decir, sus condiciones de existencia. Se abre así una nueva historia, no menos circunstancial, que parece acercarnos al cuadro. Las menciones temporales dan testimonio de ello, y a la espera de nuestro cuadro, el texto nos da otros: en el capítulo 1 son las $11 \mathrm{~h}$. (II, $1,78)$, la escena está iluminada con una linterna (II, 1, 82); luego es medianoche (II, 3, 107) y finalmente las 3 de la mañana (II, 3, 119). Durante ese tiempo, lentamente desgranado, volvemos a los Once: el tema del encargo es develado pero es un secreto que debe ser mantenido y que solamente la literatura revela aquí por anticipación. El capítulo 2 comienza designando un nuevo punto ciego: la causa de este encargo del cuadro. La misma depende de la situación política de la época, una vez más abordada por un cuadro: una trinidad formada por Robespierre, Danton y Hébert, constituyendo juntos la imagen d'Epinal (II, 2, 95-96) y proveyendo un nuevo enfoque de los Once. El narrador va a distinguir, en efecto, sub-grupos para formar una nueva Trinidad, para responder a un sacramento nuevo, la Trinidad de la Salvación Pública. El primer sub-grupo está formado por tres figuras mayores: Robespierre, Saint-Just y Couthon. El segundo, por los «sabios de manos sucias»: Carnot, Barrère, Prieur, Prieur, Jeanbon, y Lindet, en número de seis. El último está formado por dos independientes exaltados e imprevisibles: Billaud y Collot. Es interesante hacer notar que estos once personajes, que constituyen once roles, se reparten según una Trinidad y forman a su manera una dimensión sagrada, no religiosa ciertamente, pero sin embargo con todos los atributos de la religión. La posibilidad del cuadro es así establecida y el pintor puede entrar en acción, pues 
representar es un acto. Va a representarlos en representación, es decir en la encarnación de su rol (y no por sus aspiraciones artísticas frustradas) sobre todo por la especificación de sus vestimentas. Es así que asistimos al retorno final del cuadro de los Once (II. 2, 104-105) por la reiteración de la enumeración de los miembros, que aparece otra vez aquí, con la mención de sus nombres en el mismo e invariable orden («de izquierda a derecha: Billaud, Carnot, Prieur (Pierre-Louis), Prieur (Claude-Antoine), Couthon, Robespierre, Collot, Barrère, Lindet, Saint-Just, Saint-André» (II, 2, 105 como en I, 3, 43) como un puro regodeo del lenguaje, reiteración de su función —es once veces la misma: once comisarios, y finalmente por la descripción de cada uno. Están abordados por sus vestimentas: estamos frente a siete «trajes de pekin», dos «hopalandas», tres "pares de botas», cuatro "pares de zapatos con hebillas", un "traje de oro», tres "penachos de pluma» (uno sobre la cabeza, uno sobre la mesa, uno en la mano) y once "cuellos alla paolesca». El parecido de los elementos de la vestimenta hace caer a los once comisarios en una relativa indistinción. Se los ve, no se los distingue.

El capítulo siguiente nos confirma que no se ve nada, puesto que implementa una triple pantalla de noche: es Nivoso, estación en que la luz del día es muy tenue, es el Terror, que suprime toda claridad para hacer pesar una amenaza constante e inquietante, es la noche, el fuego está apagado, no se ve literalmente nada. Michon nos propone captar esta cualidad nocturna por dos referencias especializadas en zonas de oscuridad: el Caravaggio y Shakespeare, la pintura una vez más y el teatro, al que hace eco "ese viejo teatro de sombras» (II, 2, 93) que es la política, tema declarado de baja estofa, que pertenece a la vez al pasado y a la naturaleza de la acción evocada (los partidos, luchas de influencia, estrategias y otras astucias de la malignidad humana).

La atmósfera descrita es en efecto a la vez nocturna y crapulosa. Shakespeare provee la imagen (la representación adecuada y típica de los tres patrocinantes de la pintura: «Collot en el rol de Macbeth, Bourdon en Iago, Proli en Shylock» (II, $4,122)$. Corentin mismo nutre la metáfora literaria, puesto que «juega el papel de San Mateo, que no está en Shakespeare» (id.). Y excepcionalmente participa en la imagen shakesperiana así suscitada al designar a los Once que se propone pintar como una "farsa paga» (II, 3, 108). Además, San Mateo no está en Shakespeare pero está en la obra del Caravaggio y está tres veces: para evocar su vocación, su martirio y su comercio con el Ángel. 


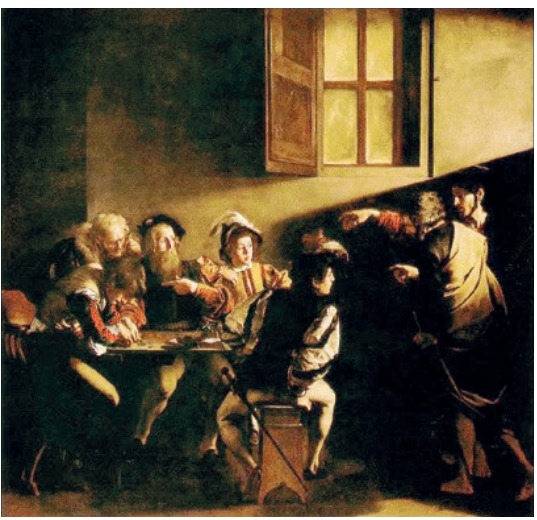

La vocación de San Mateo.

Caravaggio. 1599

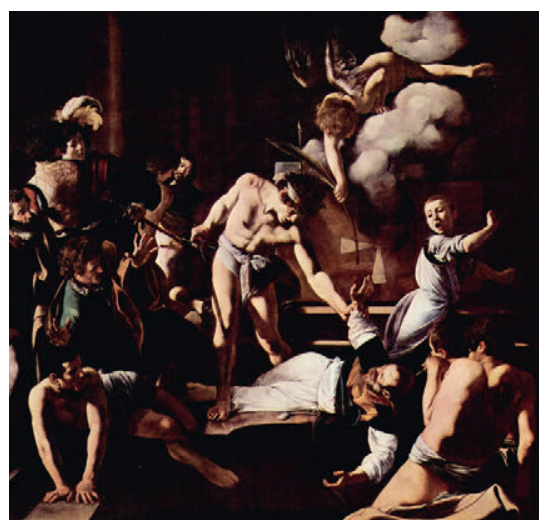

El martirio de San Mateo.

Caravaggio. 1600
202203

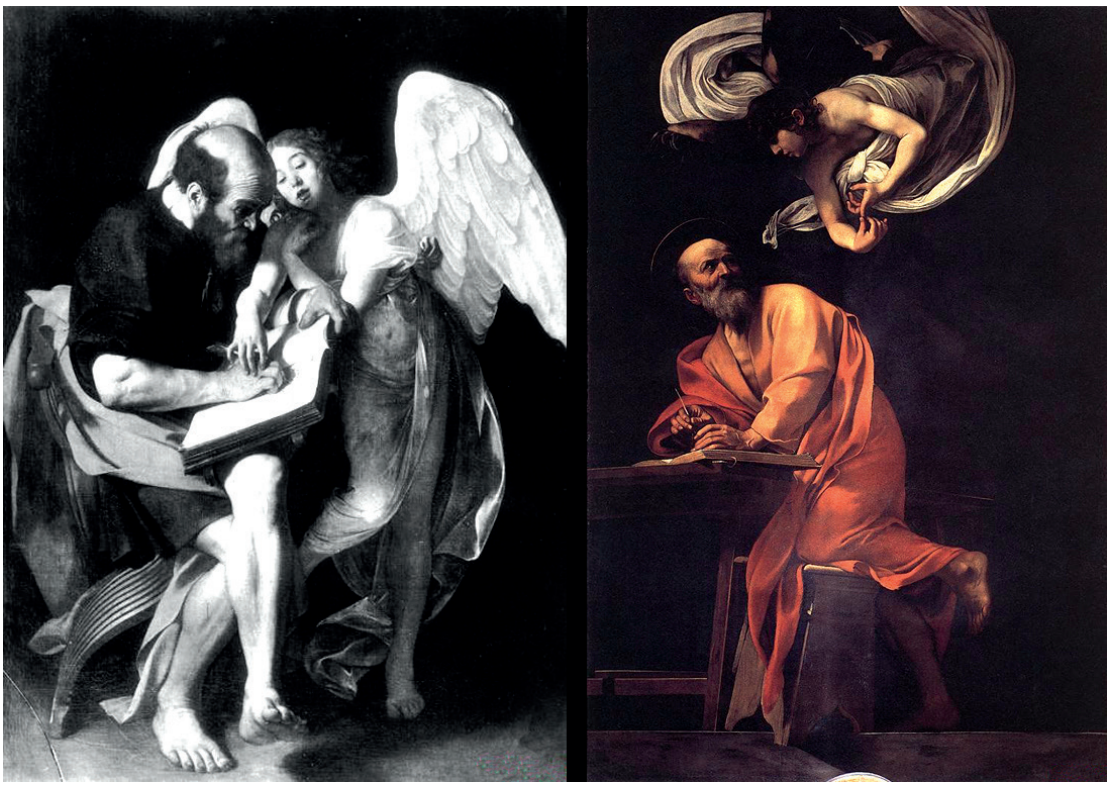

San Mateo y el Ángel. Caravaggio. 1602

(dos versiones sucesivas) 
Michon piensa tal vez en su vocación en ese momento, y avala una vez más la representación teatral por una retórica inspirada en Víctor Hugo, por grandes efectos estilísticos, muy identificables e imposibles de ignorar.

Puesto que decididamente el famoso cuadro se aleja tanto como parece acercarse, otro cuadro se substituye a él, una naturaleza muerta muy simbólica, casi crística, que muestra sobre una mesa el pan y el vino y que es una manera de vanidad también. No a causa del cráneo (que no está) sino de la osamenta de una santa, rodando sobre la mesa fuera de una fea bolsa de tela. El tiempo se inmoviliza en esta noche de encargo, en ese tiempo de concepción del cuadro y se enrolla indefinidamente. La mesa de la Cena se reconstituye eternamente, con las cartas y los dados, accesorios crísticos de la pasión que aparecen siempre en la Historia humana. Se comprenderá cómo tal tema está nutrido por tantas representaciones, ciertamente pictóricas, entre otras. La idea de una enumeración exhaustiva da vértigo.

¿Sería porque la concepción, la idea misma de ese cuadro es un secreto, que el cuadro es invisible? Responde a un doble motivo: su causa (II, 3, 110-114) es una estratagema política que consiste en dar existencia a un Comité que no existe aún, justamente para darle consistencia, a fin de producirlo luego como un arma de doble filo. Es decir, que se puede leer en dos sentidos antagonistas: como apoteosis o como ajusticiamiento de Robespierre, cuyo futuro es incierto. El cuadro se revela así como un arma de guerra innoble, «un golpe bajo» (II, 3, 112). Lo que nos dice el narrador, el patrocinante (el personaje), ya que no lo dice al pintor, que sin embargo hace así su cuadro. Sin embargo, el mismo narrador comienza por decirnos que esta causa es un enigma (II, 2,93). Tenemos fundamentos entonces para preguntarnos si esta revelación que se despliega a lo largo de cuatro páginas no es una nueva manipulación: ¿presenta un hecho o una hipótesis? Surge de la concepción de este cuadro la idea de presentar el retrato de un tirano con once cabezas. Está la elección de las referencias: una nueva Hidra de Lerne, una suerte de Gorgona que petrificaría con la mirada a aquél que la mira, lo que explicaría al menos el cuidado que tiene el narrador por mantener su cuadro invisible. Desde el punto de vista de la representación entramos en el terreno de la mitología. Es necesario convocar este terreno para sostener el tema de tal cuadro, que finalmente no puede suscitar más que el temor. Es la representación de una cena amañada, donde faltaría sobre todo Cristo porque el alma colectiva aquí representada no es la del pueblo de 1789, sino la del tirano, de suerte que no figuran allí once apóstoles, sino once Papas — once tiranos, lo vimos antes, bajo el tema de parricidas (II, 4, 131). Es por eso que luego el narrador evoca once criaturas de pavor y de furia: once bestias divinas. Delante de ellas, ¿quién puede sostenerse? El cara a cara es imposible, la mirada es imposible. Como cara al sol o a la muerte, es bien conocido, diría Michon.

El narrador puede hacer reflejar el esbozo del cuadro realizado por Géricault, o las doce páginas que Michelet le habría dedicado. Dos substitutos de los Once prometidos desde el título. Las representaciones dilatorias se multiplican, nada está de más: literatura novelesca o épica, poesía, teatro, pintura de historia o religiosa, mitología, todas las épocas mezcladas, el narrador llena la invisibilidad de ese cuadro por representaciones tan múltiples como diversas. Las convoca, las inventa también. Es su juego, su rol. Al final, se piensa que se ha llegado: «estamos ahí, delante» (II, 4, 133). Es una hipotiposis paradójica pues estamos (evidentemente) delante... de nada. Nada fijo, nada estable, nada fiable. Pero esta nada no es nada, esos once roles, 
diversa, y escasamente, retenidos por la memoria de la Historia, es precisamente una idea de la Historia. Es la Historia como puro Terror: fascinante y aterrador.

Entonces, ¿es todo? Esa Nada, el Terror en persona, por así decir, el riesgo de la noche total, ¿¿nada para ver? Queda el espacio del juego, un juego no inocente. Estaba inscripto desde el comienzo. Veamos el juego de Pierre Michon en sus primeras líneas.

Michon comienza su texto con un retrato que da al texto función de cuadro y precisamente un cuadro intangible, invisible al ojo, pero legible porque construye imagen.

Era de tamańo mediocre, discreto, pero retenía la atención por su silencio febril, su jovialidad oscura, sus maneras alternativamente arrogantes y oblicuas — torvas— se ha dicho. Es así al menos que se lo veía más tarde.

El personaje es desde el principio pronominal, es decir, sin nombre. Brilla por su discreción (su «silencio», y su calificación de «febril» no cambia nada; o sus maneras «oblicuas»). La mención "se ha dicho», lo mismo que la representación pronominal nos hace cómplices y contables de un saber que para comenzar, no se tiene. No se sabe de quién habla, sino de un personaje que por añadidura es esquivo.

Existe un retrato pintado de este personaje. Se sabe exactamente dónde se sitúa. Se podría casi ir a verlo: a Wurtzbourg. Es un poco lejos. Pero es un lugar conocido y por una vez, la cosa es segura; el célebre pintor Tiépolo lo ha retratado. Aunque, está en el cielorraso, «entre cien príncipes, cien condestables (...) esclavos y mercaderes, changarines». Nuestro personaje estará un poco perdido, en ese «mundo en su recensión exhaustiva». Como está identificado, sin embargo, el paje que porta la corona sobre un cojín, retomamos la esperanza. Uno se da cuenta entonces que se trata menos de un retrato que de un tipo, puesto que responde a una cita de Veronese. Finalmente ese paje, es entonces nadie. Sobre esta decepción inaugural, un segundo cuadro aparece, así como nuestro personaje, entre los figurantes: se trata del Juramento del Jeu de Paume, de David. El famoso personaje está de espalda, está identificado a veces como Marat. Pero, tiene en la mano un diario, cuya creación data de septiembre de 1789. Ahora bien, este juramento es un acontecimiento histórico que aconteció el 20 de junio de 1789. Este anacronismo mantiene al menos una invisibilidad fáctica que habrá que admitir. Una tercera referencia surge, por asociación de idea, a propósito de un autorretrato de Rembrandt del que se ha descubierto que no se trataba de él, y que es objeto de otras dos hipótesis de identificación. Una cuarta y última referencia aparece finalmente en este comienzo de texto: un retrato atribuido a Vivant Denon, inmediatamente descalificado: es una falsificación. Vemos entonces, para comenzar, que si queremos ver al pintor, es decir a su mínimo retrato, por lejano y fugitivo que sea, como el texto nos invita, estaremos decepcionados. La apariencia aportada por esas cuatro referencias no permite siquiera percibirlo, pues está siempre recubierto por una ficción, una referencia que le es extranjera y lo aleja de sí mismo en beneficio de un tipo al que se ve en su lugar. La apariencia no es nada, puesto que responde a formas preexistentes salidas de tipos y de cánones descriptivos de una época. Es así que la levedad de Michon se ejerce aquí a toda máquina: todo escenario parece una fantasía de la imaginación, estamos entregados a la buena voluntad de un narrador bromista que nos lleva de la nariz donde él quiere, si lo supiera, y tal vez a ningún lado, si es verdad que no hay nada que ver. El procedimiento no es nuevo: 
Usted ve, lector, que estoy en buen camino, y que solo dependerá de mí hacerle esperar un año, dos años, tres años, el relato de los amores de Jacques, separándolo de su amo y haciéndolos correr a cada uno todos los azares que me gusten. ¿Qué es lo que me impediría casar al amo y hacerlo cornudo? ¿Embarcar a Jacques a las islas? ¿Conducir allí a su amo? ¿Traerlos de nuevo a Francia a los dos en el mismo barco? ¡Qué fácil es hacer cuentos! Pero se liberarán uno y otro de una mala noche y usted de esta demora.

Esta «demora» impuesta por Diderot al comienzo mismo de Jacques el fatalis$t a$, que sería excesivo designar como una tortura, es un gesto muy moderno de decepción de la espera del lector suscitada por el texto mismo. Es la entrada en un juego que el lector, si persevera, debe seguir, según las reglas que descubre, como aquí, sobre la marcha, o más bien, las reglas narrativas de las que descubre aquí una formulación, pues son, como el arte, eternas. De lo que se trata es de la conducta del deseo. Pero esta dimensión aquí está declarada claramente puesto que el narrador habla directamente a su lector, lo apostrofa por el trato de usted, lo que hace que el texto se imponga violentamente a su lector, a la manera de $\mathrm{La}$ Caida de Camus. Es decir, es lo que importa de un soliloquio conducido por el narrador que impone su relato en una oleada ininterrumpida de palabras, previendo de tanto en tanto, alguna objeción o pedido de parte de su interlocutor, bien presente, pero mudo. Esta palabra es tan invitante y esclarecedora como tiránica y torturadora, respondiendo así por ese régimen de oxímoron a ese otro régimen con el que el narrador caracteriza la época del siglo XVIII, que por cierto no termina como comenzó: «el siglo de hierro del placer de vivir» (I, 2, 39). El autor juega también aquí (lo dice de vez en cuando), con imágenes estereotipadas, puesto que el reinado de Luis XV (el rey «bien-amado») es el de una excepcional prosperidad (1715-1774), de allí el "placer de vivir». Mientras que el de Luis XVI comienza en un Reino arruinado y termina con la decapitación del rey: es el «siglo de hierro».

Es por eso que todos los efectos dilatorios del relato (y sobre todo las historias genealógicas, puesto que la vida del pintor se esclarece con la de sus padres y abuelos, y hasta su bisabuelo materno) en relación a los Once, parecen una estrategia general de retraso sabiamente elegida. Sí, el cuadro es un secreto, sí, representa un grupo oficial aún inexistente al momento de la concepción del cuadro, es decir que ese cuadro constituye un gesto político él mismo sometido, en la interpretación que recibirá, al régimen de oxímoron de un sentido de doble disparador, de un arma de guerra de doble filo, que condena o ensalza a Robespierre, con sus acólitos, según el oportunismo que la situación ofrecerá. En un sentido ¿por qué recurrir a la ficción, como una máscara mal ajustada, expresamente, a lo real? Es que no se trata solamente de divertirnos con la multiplicación de demoras impuestas. Se puede comprender que un autor busque dar una aclaración biográfica exhaustiva para ayudar a comprender su obra. Esto es lo que refuta Daniel Arasse. Pero es también lo que se ha hecho antes y hoy todavía. Aquí todas las historias desarrolladas no son cantos de sirena (por lo que nos seducen tanto como nos pierden) y es a lo que apunta Pierre Michon.

Es en este doble gatillo oximorónico, que parece la esencia de todo régimen de representación que, obedeciendo a la palabra que Pierre Michon no deja de enunciar la reversión, donde pintura y literatura se vinculan y se ayudan. Su logro es convencernos de que la pintura no muestra más que el texto. Que por todas partes las producciones de imágenes permanecen inacabadas, fuera de alcance, 
insatisfactorias para nuestro deseo de ver y de saber. En las profundidades de la revelación del secreto mejor guardado, ningún régimen de representación puede colmar la expectativa. Política e historia por un lado, imaginación y ficción por el otro, las interpenetraciones que fundan el oxímoron producen una fluidez y un flujo interminable entre lo real y la ficción. La mirada es el vector de transporte de un régimen al otro, lo que hace de nuestra lectura misma un acto consecuente. Es lo que hace también objeto de una insistencia particular: lo que vemos, lo que queremos o deseamos ver, y lo que no vemos.

De este modo podemos explicar cómo y por qué Pierre Michon multiplica las referencias literarias, pictóricas, artísticas. No es porque la mirada sea deficiente y hubiera que paliar ese defecto a través de muchas representaciones. Se apilan lo suficiente en nuestra mente sin su intervención — suscribo a esto yo misma agregando a Diderot, Claudel, o el mismo Hugo. Por qué no: ¿̨la alianza de lo grotesco y lo sublime no conviene a la oximorónica representación de la que estamos hablando? Él mismo, en un fuera de texto, remite igualmente el recurso a Claudel: podría ser por su expresión a propósito del arte pictórico, «el ojo escucha», pues la mirada, en efecto, está relacionada con la voz. Podría ser también por la Sombra Doble, ese personaje que él inventa en la Zapatilla de satén para figurar la pareja prohibida e imposible de Don Rodrigo y Doña Proeza, y que viene a quejarse de su existencia alimentada por lo imposible. En el texto, sin embargo, las referencias son todas muy precisas: pertenecen todas al siglo doble del placer de vivir y del hierro.

La madre del pintor, Suzanne, es un ejemplo emblemático de ello pues anticipa el personaje de Emma Bovary (1857), moldeado con historias novelescas vagas que la desrealizan particularmente porque está ilustrada por Watteau, el pintor de esas fiestas galantes impregnadas de ligereza y de gracia de comienzo del siglo $y$ de Manon Lescaut (1731) la del conocido destino trágico. Como para el hijo, el retrato de la madre es tratado por referencia a los códigos de belleza en uso, esos cánones generales valen como rasgos distintivos de su rostro. Precisamente, la descripción de su belleza se declina según los rasgos empleados en Casanova (1725-1798), Sade (1740-1817), Bernardin de Saint-Pierre (1737-1814) y Rousseau (1712-1778). Aquí una vez más, el régimen oximorónico de la representación está en vigencia, puesto que la importancia de la naturaleza profesada por estos dos últimos se cruza con la de la vigencia del libertinaje de los dos primeros de manera que se podría pensar que la pintura de la belleza se distingue en unos por relación con los otros. Pero en realidad, los cánones de la belleza abren ampliamente el campo de posibles, para desplegar un retrato que no es uno, puesto que designa un tipo (una representación) y no una persona real y distinta.

La belleza es una imagen diversamente tratada, pero parece inmutable. No se sale de la imagen que es siempre falaz, nunca particular. Siempre general, designa otra cosa diferente a lo que muestra espontáneamente. Es por eso que decididamente no se ve nada. Hay que agregar a esta Suzanne genérica que enriquece a su vez el mito, desviándolo. En el mito, y la pintura ha hecho de esto su garante opulenta, desde los siglos anteriores (por Rembrandt, El Tintoreto, Manet, Veronese, Rubens, tantos otros...), la escena de Suzanne en el baño la presenta ante las miradas concupiscentes de unos viejos. La historia es bíblica, ya en el libro de Daniel: Suzanne, observada mientras toma su baño, rechaza las propuestas deshonestas de dos viejos. Para vengarse, estos la acusan de adulterio y la hacen condenar a muerte, pero el profeta Daniel, todavía adolescente, prueba su inocencia y hace condenar a los viejos. 


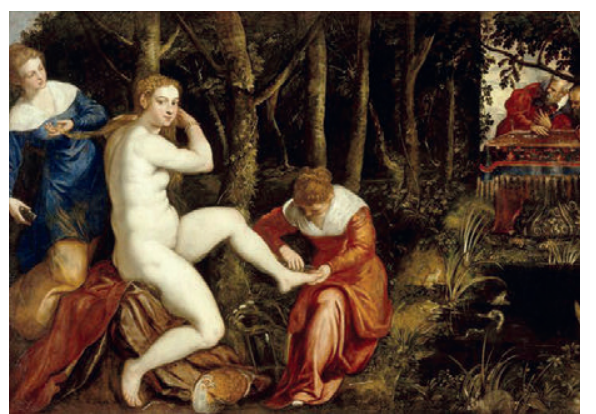

El Tintoreto (1550)

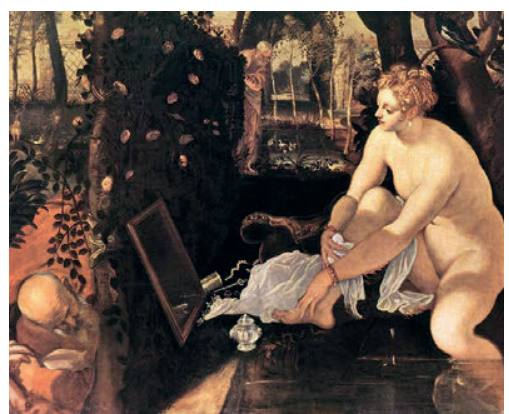

El Tintoreto (1555-1556)

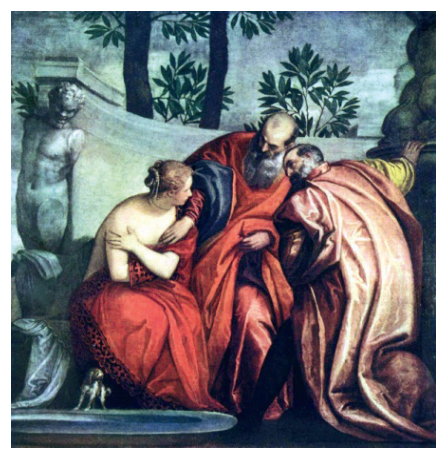

Veronese (1580)

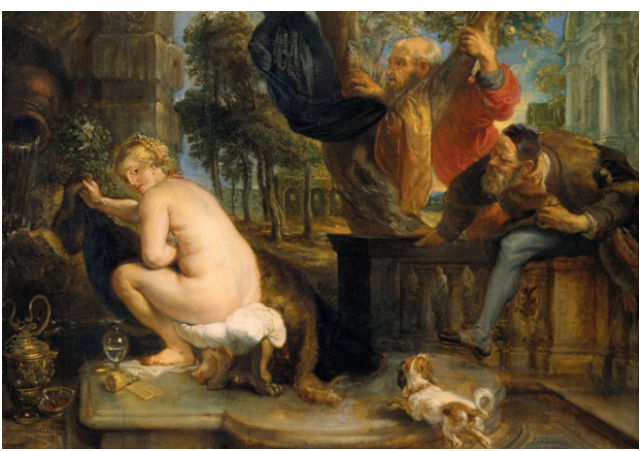

Rubens (1636-1639)

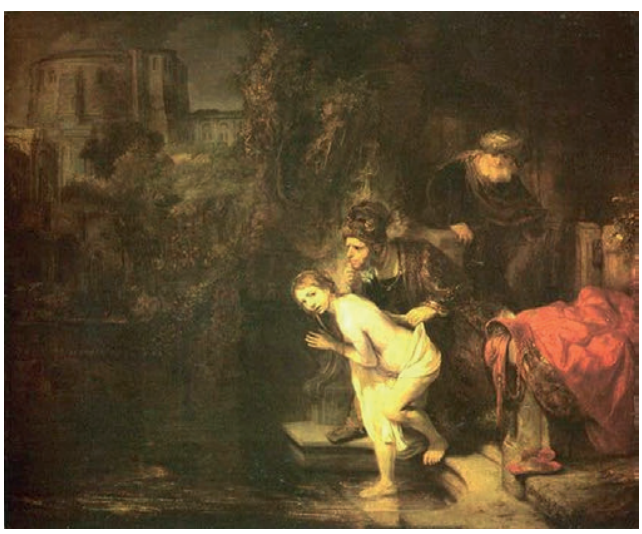

Rembrandt (1647) 
Casada o no, Suzanne está en general calificada de casta, a causa de su actitud con respecto a la concupiscencia de los dos viejos. Aquí el bańo tiene lugar en el Loira, la mirada de deseo es tenida por un solo hombre viejo, que será el padre de Corentin. Suzanne, ciertamente, es casta, como el personaje original de esta escena, pero hasta cierto punto. Suzanne también condensa en ella una suma de representaciones que activa ad libitum, según la competencia y el deseo del lector: Michon no está incesantemente detrás de nosotros, para soplarnos las fuentes. Pero se ve bien activo ese trabajo de la multiplicación de las representaciones. Ese efecto es al menos bien buscado por Michon.

$\mathrm{Si}$ el retrato responde a tipos de época, las actividades ociosas de Suzanne correspondiendo a su origen noble, crean una lógica textual irrefutable: el tapiz (se trata de red, de tejido, el texto no está lejos) y de la poesía anacreóntica (tratando la voluptuosidad ligera, en fase con la referencia a Watteau). En esta suerte de lógica impertinente del soliloquio, su hijo no puede ser otra cosa sino escritor. Jean Echenoz se acordará de esto cuando su personaje femenino, en el comienzo de Nosotros tres, subida cuando hace autostop a un auto Mercedes conducido por un hombre, se encuentra luego bautizada en la novela con el nombre de Mercedes.

Ese texto, que promete ver un cuadro, que nos cuenta, en realidad, sus condiciones de aparición, es un canto de sirena en tanto nos engańa, es un tejido de historias destinado a fundar la terrible lógica de la Historia. Michon opera aquí completamente a la inversa de Daniel Arrasse: no ha cesado de recurrir a informaciones externas al lienzo, a tornar el detalle ineficaz, a repetir un saber que se nos impone por la fuerza, como tantas otras pistas falsas. Pero más allá de la postura de Daniel Arasse, Michon, que no es historiador del arte, nos muestra que la tela está fundada sobre un vacío, sobre una ausencia de modelo, sobre un objeto que no existe. No se ve nada... más que cuentos: más que literatura. ¿Es esta una mirada oblicua? Cuando no hay nada para ver ¿̨hay ya algo para leer? La vanidad que se insinúa por todas partes culmina en el temor, como el placer de vivir bajo el hierro, o Louis XV bajo Louis XVI. La levedad de la diversión, el retraso registrado por la demora son dos límites que se corrigen a fin de obtener las condiciones necesarias de representación de lo irrepresentable o del objeto cuya visión es insostenible.

\section{Notas}

${ }^{1}$ Grand prix du roman de l'Académie Française, este libro está compuesto por dos partes, ellas mismas subdivididas en cuatro capítulos. Las referencias a este texto estarán a partir de ahora dadas entre paréntesis, parte en números romanos, capítulo y luego página en número arábigo. ${ }^{2}$ Lemosino: habitante de la región de Limoges, Francia. Esta región es conocida como una zona rural, recluida y alejada de todo centro cultural. Aun cuando todos sabemos que los artistas nacen en cualquier lugar, y no solamente en las regiones con alta densidad cultural, los Lemosinos se presentan a priori como particularmente incongruentes. Es por esto que ver nacer en esta región a un futuro pintor es una invención agra- 
dable. Es por tanto una auto-ironía de parte del escritor Pierre Michon, nativo y habitante durante toda su vida de esta región. Se puede volver a escuchar el planteo de Montesquieu en sus Cartas Persas: ¡¡ómo se puede ser Persa?... que se corresponde aquí con: ¡cómo se puede ser Lemosino?

\section{Referencias bibliográficas}

Michon P. (2009). Les Onze. Verdier.

Arasse D. (2000). On n'y voit rien. Denoël.

Diderot D. (1796). Jacques le fataliste et son maître (1875). https:// fr.wikisource.org/wiki/Jacques_le_Fataliste_et_son_maître

\section{Bibliografía sobre Les Onze de Pierre Michon}

Entrevistas de Pierre Michon

Michon, P. (2007). Le roi vient quand il veut. Propos sur la littérature. Reedición revista y aumentada con un index. Albin Michel, [2016]. MontréMY, J.-M.DE (10 abril 2009). Michon, le Tiepolo de la Terreur. Livres-Hebdo, (772).

Guichard, T. (mayo 2009). Fabrique de légendes. Le Matricule des Anges, dossier Pierre Michon (103).

Jeancourt-Galignani, O. (mayo 2009). Le sacré, la bête et le dieu. Transfuge (30).

Sobre Les Onze

- Obras

Audi, P. (2015). Terreur de la peinture, peinture de la Terreur. Sur Les Onze de Pierre Michon. William Blake and Co.

Farron, I. (2011). L'appétit limousin. Les Onze de Pierre Michon. Verdier.

- Estudios

Demanze, L. (2014). Pierre Michon: l'Histoire en personne. Érudition, fabulation, imagination. En Panter, M. et al. (dir.). Imagination et Histoire. Enjeux contemporains. Presses universitaires de Rennes.

Mitterand, H. (2016). Histoire/Fiction: Les Onze, de Pierre Michon. Studia Romanica, Debrecen (Hongrie), Fasc. XXVII, À la croisée de deux cultures.

Nicole, E. (mars 2010). Le tableau qui manquait à la Révolution. Pierre Michon, Les Onze. Critique (754).

Petitier, P. (octobre 2009). Une houppelande couleur de fumée d'enfer. Écrire l'histoire (4) «Le Détail 2».

VIala, A. (2005). Pierre Michon historien. Critique (694). Actes de la journée d'étude «Pierre Michon et l'Histoire».

- Sitios internet

Campion, P. (2017). Une voix, soi-disant. Sur Les Onze de Pierre Michon. http://pierre.campion2.free.fr/cmichon_les11.htm

Cormary, P. (2010). La Révolution et ses réversions (sur Les Onze de Pierre 
Michon). http://pierrecormary.hautetfort.com/archive/2010/04/22/larevolution-et-ses-reversions-surles-onze-de-pierre-micho.html

Demanze, L. (2014). Les Scénographies picturales de Pierre Michon. Fixxion (8). http://www.revue-critique-de-fixxion-francaise-contemporaine.org/rcffc/article/view/fx08.08/843

Guilors, B. (2010-2011). Pierre Michon, Les Onze: un peintre et son chefd'œuvre. Site Présence de la littérature-Dossier Michon@SCÉRÉN-CNDP. 